\title{
Effect of induced subclinical hypocalcemia on physiological responses and neutrophil function in dairy cows
}

\author{
N. Martinez, ${ }^{\star}$ L. D. P. Sinedino, ${ }^{\star}$ R. S. Bisinotto, ${ }^{\star}$ E. S. Ribeiro, ${ }^{\star}$ G. C. Gomes, ${ }^{*}$ F. S. Lima, ${ }^{\star}$ L. F. Greco, ${ }^{\star}$ \\ C. A. Risco,† K. N. Galvão,† D. Taylor-Rodriguez, $\ddagger$ J. P. Driver, ${ }^{\star}$ W. W. Thatcher, ${ }^{\star}$ and J. E. P. Santos ${ }^{\star 1}$ \\ *Department of Animal Sciences, \\ †Department of Large Animal Clinical Sciences, and \\ $\ddagger$ School of Natural Resources and Environment, University of Florida, Gainesville 32611
}

\section{ABSTRACT}

The objectives were to study the effects of induced subclinical hypocalcemia [SCH, blood ionized $\mathrm{Ca}$ $\left(\mathrm{iCa}^{2+}\right)<1.0 \mathrm{~m} M$, without recumbency] on physiological responses and function of immune cells in dairy cows. Ten nonpregnant, nonlactating Holstein cows were blocked by lactation and assigned randomly to a normocalcemic (NC; intravenous infusion of $0.9 \% \mathrm{NaCl}$ i.v. plus $43 \mathrm{~g}$ of oral $\mathrm{Ca}$, as $\mathrm{Ca}$ sulfate and $\mathrm{Ca}$ chloride, at -1 and $11 \mathrm{~h}$ ) or an induced SCH [SCHI, $5 \%$ ethylene glycol tetraacetic acid (EGTA), a selective $\mathrm{iCa}^{2+}$ chelator, intravenous infusion] treatment for $24 \mathrm{~h}$, using a crossover design. The sequence of treatments was either NC-SCHI or SCHI-NC, with a 6-d washout period. Ionized Ca was evaluated before, hourly during the infusion period, and at 48 and $72 \mathrm{~h}$, to monitor concentrations and adjust the rate of infusion, maintaining blood $\mathrm{iCa}^{2+}<1.0 \mathrm{~m} M$ in SCHI throughout the 24-h infusion period. Additional measurements included heart and respiratory rates, rectal temperature, dry matter intake, rumen contractions, whole-blood $\mathrm{pH}$, concentrations of glucose and $\mathrm{K}$ in whole blood, concentrations of total $\mathrm{Ca}, \mathrm{Mg}$, nonesterified fatty acids, $\beta$-hydroxybutyrate, and insulin in plasma, and urinary excretion of Ca. Total and differential leukocyte count in blood was also performed. The concentration of cytosolic $\mathrm{iCa}^{2+}$ in neutrophils and lymphocytes was quantified and neutrophil function was assayed in vitro. Infusion of a $5 \%$ EGTA solution successfully induced SCH in all SCHI cows, resulting in decreased blood $\mathrm{iCa}^{2+}$ concentrations throughout the 24 -h treatment period $(0.77 \pm 0.01$ vs. $\left.1.26 \pm 0.01 \mathrm{mM} \mathrm{iCa}^{2+}\right)$. Induction of SCH reduced dry matter intake on the day of infusion $(5.3 \pm 0.8$ vs. 9.1 $\pm 0.8 \mathrm{~kg} / \mathrm{d})$ and rumen contractions $(1.9 \pm 0.2$ vs. 2.7 \pm 0.2 contractions $/ 2 \mathrm{~min}$ ) for the last $12 \mathrm{~h}$ of infusion. Cows in SCHI had decreased plasma insulin concentration $(1.44 \pm 0.23$ vs. $2.32 \pm 0.23 \mathrm{ng} / \mathrm{mL})$ evident

Received August 22, 2013.

Accepted November 1, 2013.

${ }^{1}$ Corresponding author: jepsantos@ufl.edu between 6 and $18 \mathrm{~h}$ after the beginning of the infusion, accompanied by increased concentrations of glucose $(4.40 \pm 0.04$ vs. $4.17 \pm 0.04 \mathrm{mM})$. Plasma nonesterified fatty acids concentration was greater for SCHI than NC cows $(0.110 \pm 0.019$ vs. $0.061 \pm 0.014 \mathrm{mM})$. Neutrophils of cows in SCHI had a faster decrease in cytosolic $\mathrm{iCa}^{2+}$ after stimulation with ionomycin $(9.9 \pm 1.0$ vs. $13.6 \pm 1.4$ Fluo-4:Fura Red post-end ratio) in vitro. Furthermore, induction of $\mathrm{SCH}$ reduced the percentage of neutrophils undergoing phagocytosis $(22.1 \pm 2.1$ vs. $29.3 \pm 2.1 \%$ ) and reduced the oxidative burst response after incubation of pathogenic bacteria (16.1 \pm 1.7 vs. $24.2 \pm 1.7 \%$ ). Subclinical hypocalcemia compromised appetite, altered metabolism, and impaired function of immune cells in dairy cows.

Key words: dairy cow, immune function, metabolism, subclinical hypocalcemia

\section{INTRODUCTION}

Dairy cows have between 2 and $4 \mathrm{~g}$ of $\mathrm{Ca}$ in blood, half of which is in the ionized form $\left(\mathbf{i C a}^{2+}\right)$. On the first day of lactation, synthesis and secretion of colostrum impose major losses of Ca equivalent to 7 to 10 times the amount of Ca present in blood (Horst et al., 2005). To cope with this rapid Ca loss and maintain normocalcemia, homeostatic mechanisms have to be in place to increase the influx of $\mathrm{Ca}$ into the blood (Goff, 2008). However, the inability of the cow to fully reestablish concentrations of $\mathrm{Ca}$ in blood, through intestinal absorption or bone resorption, likely explain the high prevalence of subclinical hypocalcemia $(\mathbf{S C H})$ in primiparous (25\%) and multiparous (47\%) cows (Reinhardt et al., 2011). Change in cytosolic $\mathrm{iCa}^{2+}$ is a component of important cellular messenger systems, and increased cytosolic $\mathrm{iCa}^{2+}$ concentration is required for regulation of important processes such as neurotransmission, muscle contraction, cell metabolism, cell growth, cell proliferation, and activation of immune cells, among others (Saris and Carafoli, 2005; Parekh, 2006; Vig and Kinet, 2009). Cows with milk fever are at increased risk of developing other periparturient 
problems, including dystocia and ketosis (Curtis et al., 1983), displaced abomasum (Massey et al., 1993), uterine prolapse (Risco et al., 1984), and retained placenta (Melendez et al., 2004). The increased risk of developing these conditions is likely mediated by several factors, including the effects of low $\mathrm{iCa}^{2+}$ suppressing smooth muscle contractions (Hansen et al., 2003). Furthermore, hypocalcemic cows have increased plasma concentrations of cortisol (Horst and Jorgensen, 1982), reduced proportion of neutrophils with phagocytic activity (Ducusin et al., 2003; Martinez et al., 2012), and impaired mononuclear cell response to an antigen-activating stimulus (Kimura et al., 2006). This reduction of immune response has linked hypocalcemia to infectious diseases of bacterial origin such as metritis (Martinez et al., 2012) and mastitis (Curtis et al., 1983).

Although the consequences of SCH have not been fully established, affected cows during the first 3 DIM had marked increases in lipid mobilization and a decreased percentage of neutrophils with phagocytic and killing activities, and were at much greater risk of developing metritis and puerperal metritis compared with normocalcemic cows (Martinez et al., 2012). In corroboration with these findings, lactating grazing cows with $\mathrm{SCH}$ in the first 7 DIM had increased incidence of metritis and endometritis, along with higher concentrations of NEFA and BHBA in plasma (Ribeiro et al., 2013). Descriptive data from cows induced to have $\mathrm{SCH}$ indicated depressed feed intake and rumination (Hansen et al., 2003). Collectively, these studies suggest that $\mathrm{SCH}$ is associated with immune dysfunction, exacerbated negative nutrient balance, and greater incidence of uterine diseases in early postpartum dairy cows. Despite the strong link between SCH and peripartum diseases, most studies have been observational in nature and performed during the early postpartum period, when it is difficult to isolate the effect of inadequate concentrations of $\mathrm{Ca}$ and $\mathrm{iCa}^{2+}$ in blood from the combined metabolic and endocrine disturbances that might influence immune function.

The hypotheses of the current study were that SCHI, defined as blood $\mathrm{iCa}^{2+}$ concentration $<1.0 \mathrm{~m} M$ without recumbency, would reduce DMI and compromise measures of energy metabolism, and reduce cytosolic concentrations of $\mathrm{iCa}^{2+}$ in leukocytes, thereby depressing measures of white blood cell function in dairy cows. Therefore, the objectives were to study the effects of SCHI on physiological responses and function of immune cells in dairy cows.

\section{MATERIALS AND METHODS}

All procedures involving cows in the study were approved by the University of Florida Institutional Ani- mal Care and Use Committee and by the University of Florida Institute of Food and Agricultural Sciences Animal Research Committee.

\section{Cows and Housing}

Ten nonpregnant, nonlactating Holstein cows from the University of Florida Dairy Unit (Gainesville) were enrolled in the study. The mean $( \pm \mathrm{SD})$ age, lactation number, and BW at enrollment were, respectively, 4.4 $\pm 0.4 \mathrm{yr}, 2.4 \pm 0.3$ lactations, and $696.8 \pm 29.2 \mathrm{~kg}$. Selection criteria involved being healthy to a physical exam at the time of enrollment and no history of disease within the last $30 \mathrm{~d}$. Cows were dried off at least $1 \mathrm{wk}$ before the beginning of the study. Cows were moved to individual stalls in the Large Animal Clinic of the Veterinary Teaching Hospital at the University of Florida (Gainesville) at least $4 \mathrm{~d}$ before initiating the study to acclimate to the experimental facilities.

\section{Intravenous Solutions}

A sterile commercial solution containing $0.9 \% \mathrm{NaCl}$ (Hospira Inc., Lake Forest, IL) was used. Ethylene glycol-bis (2-aminoethylether)- $N, N, N^{\prime}, N^{\prime}$-tetraacetic acid (EGTA, cat. no. E3889, Sigma Aldrich, St. Louis, MO) $5 \%$ solution was prepared aseptically under a laminar flow hood using $900 \mathrm{~mL}$ of sterile water (Baxter Healthcare Corp., Deerfield, IL), $50 \mathrm{~g}$ of EGTA, and $50 \mathrm{~mL}$ of $5 \mathrm{M} \mathrm{NaOH}$. The solution was continuously mixed using a vortex until salts were fully dissolved and $\mathrm{pH}$ was measured. Additional $5 \mathrm{M} \mathrm{NaOH}$ solution was added until the $\mathrm{pH}$ was adjusted to 7.4. The fully dissolved solution was then filtered using a $0.45-\mu \mathrm{m}$ bacteriological filter. The solution was then labeled and stored at $4^{\circ} \mathrm{C}$ until use within $10 \mathrm{~d}$.

\section{Experimental Design and Treatments}

The study followed a crossover design in which the 2 treatments were applied to each cow in 2 different periods. Cohorts of cows were blocked based on lactation number and, within each block, cows were assigned randomly to 1 of 2 treatment sequences. The treatments were (control) normocalcemia (NC) or induced subclinical hypocalcemia (SCHI). Therefore, the sequence of treatments for a given cow was either NC-SCHI or SCHI-NC. Treatments were administered in sequence with a 6 -d washout period between treatment administrations to minimize carryover effects.

The day of intravenous infusion was considered study $\mathrm{d} 0$. On study $\mathrm{d}-1$, all cows had the jugular groove area shaved and surgically disinfected, and an intravenous indwelling catheter (14-gauge, $140 \mathrm{~mm}$, Abbocath-T, 
Hospira) was inserted in each jugular vein. One catheter was used for continuous infusion and the other for blood sampling. Catheters were continuously flushed with heparinized solution (30 USP units of heparin sodium/mL; Sigma Aldrich) to maintain patency and they were removed on $\mathrm{d} 3$.

Intravenous infusion was performed for $24 \mathrm{~h}$ on study $\mathrm{d} 0$, starting at $0900 \mathrm{~h}$ and finishing the next morning at $0900 \mathrm{~h}$. Normocalcemic cows received a continuous infusion of a solution containing $0.9 \% \mathrm{NaCl}$, whereas SCHI cows received a continuous infusion of a solution containing 5\% EGTA with an adjusted $\mathrm{pH}$ of 7.4. The infusion was performed using a controlled infusion pump (Heska Vet IV, Loveland, CO) and rate of infusion was maintained equally between $\mathrm{NC}$ and SCHI cows and determined based on blood $\mathrm{iCa}^{2+}$ concentration of SCHI cows. Cows in SCHI received an initial infusion rate of $500 \mathrm{~mL} / \mathrm{h}$ until blood $\mathrm{iCa}^{2+}$ concentrations fell below $1.0 \mathrm{~m} M$, after which the infusion rate was modified hourly according to $\mathrm{iCa}^{2+}$ concentrations. The goal was to maintain an $\mathrm{iCa}^{2+}$ concentration between 0.7 and $0.9 \mathrm{mM}$ throughout the 24-h infusion period. Concentrations of blood $\mathrm{iCa}^{2+}$ were monitored hourly throughout the infusion period using CG8+ cartridges read by a cow-side handheld biochemical analyzer (iStat System, Abbott Laboratories, Abbott Park, IL).

Cows in the NC treatment were supplemented with one bolus containing $43 \mathrm{~g}$ of $\mathrm{Ca}$ as sulfate and chloride salts (Bovikalc, Boehringer Ingelheim Vetmedica, St. Joseph, MO) at -1 and $11 \mathrm{~h}$ relative to the beginning of the infusion period. Based on a pilot study, we observed that infusion of 5\% EGTA decreased blood $\mathrm{pH}$ of cows from 7.44 to approximately 7.39 (data not shown). Therefore, the rationale for supplementing cows with a bolus containing Ca chloride and sulfate was to ensure normocalcemia and to equalize the blood $\mathrm{pH}$ to those receiving the 5\% EGTA infusion, because of the strong anions in the salts.

\section{Urinary Excretion of Ca and Creatinine}

Urine was sampled by massaging the perineal area and waiting for a continuous stream of urine. Samples were taken immediately before the beginning of infusion and $12,24,48$, and $72 \mathrm{~h}$ later. The $\mathrm{pH}$ was immediately measured using a portable $\mathrm{pH}$ meter and samples were frozen at $-20^{\circ} \mathrm{C}$ for later analyses of concentrations of creatinine and total $\mathrm{Ca}$.

Urine samples were analyzed individually for creatinine using a commercial colorimetric method (Creatinine Urinary Detection Kit, Arbor Assays, Ann Arbor, MI). Urinary Ca was measured using an atomic absorption spectrophotometer after 1:400 dilution with 0.5\% lanthanum chloride. Each assay was performed as a single run, and the intraassay coefficients of variation (CV) for creatinine and urinary Ca were 8.3 and $3.4 \%$, respectively. Urinary creatinine has been validated as a marker to estimate daily urinary volume, assuming urinary creatinine excretion of $29 \mathrm{mg} / \mathrm{kg}$ of $\mathrm{BW} / \mathrm{d}$ (Valadares et al., 1999). Total excretion of urinary Ca was calculated based on the urinary volume per day multiplied by the concentration of urinary Ca.

\section{Feeding and Measurements of DMI}

The diet offered to cows was mixed and fed every 12 $\mathrm{h}$ as a TMR and formulated to meet or exceed the MP and ME requirements of a 650-kg nonpregnant, nonlactating Holstein cow consuming $10 \mathrm{~kg}$ of DM/d (Table 1). Diets were offered at 0900 and $2100 \mathrm{~h}$, and orts were measured immediately before each feeding. The DMI was calculated by adding the amounts consumed in two 12-h periods multiplied by the DM content of the diet after sequential drying of samples at $55^{\circ} \mathrm{C}$ and then at $105^{\circ} \mathrm{C}$.

Feed was sampled daily and dried in an air circulating oven at $55^{\circ} \mathrm{C}$ for $48 \mathrm{~h}$ and moisture loss was recorded. Dried samples were ground to pass a $1-\mathrm{mm}$ screen of a Wiley mill (Thomas Scientific, Swedesboro, NJ). Ground samples were composited for each period and then analyzed for DM $\left(105^{\circ} \mathrm{C}\right.$ for $\left.12 \mathrm{~h}\right), \mathrm{OM}\left(512^{\circ} \mathrm{C}\right.$ for $8 \mathrm{~h}$ ), sequential analysis of NDF using a heat-stable a-amylase and ADF (Van Soest et al., 1991) with the Ankom Fiber Analyzer system (Ankom Technology, Macedon, NY), and $\mathrm{N}$ using an automated quantitative

Table 1. Ingredient composition (\% of DM) and nutrient profile of ration offered to cows

\begin{tabular}{lc}
\hline Item & Value \\
\hline Ingredient & \\
Corn silage & 73 \\
Soybean hulls & 18 \\
Soybean meal, 44\% CP & 9 \\
DM, \% ( \pm SD) & $53.9 \pm 0.5$ \\
Nutrient profile, DM basis $( \pm \mathrm{SD})$ & \\
NE ${ }_{\mathrm{L}}^{1}$ Mcal/kg & $1.68 \pm 0.02$ \\
$\mathrm{OM}, \%$ & $96.0 \pm 0.2$ \\
$\mathrm{Ash}, \%$ & $4.0 \pm 0.2$ \\
$\mathrm{CP}, \%$ & $10.6 \pm 0.2$ \\
$\mathrm{NDF}, \%$ & $38.8 \pm 0.6$ \\
$\mathrm{ADF}, \%$ & $24.5 \pm 0.3$ \\
$\mathrm{Ether}$ extract, \% & $2.9 \pm 0.1$ \\
$\mathrm{Ca}, \%$ & $0.24 \pm 0.02$ \\
$\mathrm{P}, \%$ & $0.24 \pm 0.01$ \\
$\mathrm{Mg}, \%$ & $0.17 \pm 0.01$ \\
$\mathrm{~K}, \%$ & $1.04 \pm 0.02$ \\
$\mathrm{Na}, \%$ & $0.02 \pm 0.01$ \\
$\mathrm{Cl}, \%$ & $0.16 \pm 0.01$ \\
$\mathrm{~S}, \%$ & $0.11 \pm 0.01$ \\
$\mathrm{DCAD}, \mathrm{mEq} / \mathrm{kg}$ & $160.4 \pm 4.6$ \\
\hline
\end{tabular}

${ }^{1}$ Calculated at $1.8 \times$ maintenance $(12 \mathrm{~kg} / \mathrm{d})$ and based on the chemical analysis of dietary ingredients (NRC, 2001). 
combustion digestion method (Leco 628, Leco Corp., St. Joseph, MO). The energy density of the diet was estimated using analyzed feed values and calculated at $1.8 \times$ maintenance intake (Table 1; NRC, 2001). Minerals were analyzed by inductively coupled plasma mass spectrometry in a commercial laboratory (Dairyland Laboratory, Arcadia, WI).

\section{Physiological Responses}

Heart and respiration rates and rumen contractions were evaluated by auscultation using a stethoscope (Littmann Classic II, 3M, St. Paul, MN) at $-48,-24$, $0,6,12,18,24,30,36,48,60$, and $72 \mathrm{~h}$ relative to the beginning of infusion. Vaginal temperature was measured every 15 min using a data logger (Temperature Logger iButton, Maxim Integrated, San Jose, CA) attached to a blank intravaginal insert. Data on vaginal temperature were then averaged hourly from -48 to $72 \mathrm{~h}$ relative to the beginning of infusion. The average vaginal temperature between -48 and $0 \mathrm{~h}$ was considered the baseline for each cow.

\section{Concentrations of Minerals, Metabolites, and Hormones, and Blood $\mathrm{pH}$}

Blood was sampled in a $2-\mathrm{mL}$ syringe rinsed with 1,000 USP units $/ \mathrm{mL}$ of sodium heparin at -24 and $-0.5 \mathrm{~h}$, and then at hourly intervals from 1 to $24 \mathrm{~h}$ relative to infusion, and then at $26,30,36,48$, and $72 \mathrm{~h}$, for measurements of $\mathrm{iCa}^{2+}, \mathrm{K}$, glucose, and $\mathrm{pH}$ using an i-Stat analyzer (Abbott Laboratories). At each sampling point, an additional blood sample was collected in heparinized evacuated tubes (Vacutainer system, Becton Dickinson Co., Franklin Lakes, NJ), placed in ice, and then centrifuged within $2 \mathrm{~h}$ at 2,000 $\times g$ for 15 min for plasma separation. Plasma was frozen at $-20^{\circ} \mathrm{C}$ until analyses, and plasma samples were analyzed for concentrations of total $\mathrm{Ca}, \mathrm{Mg}$, BHBA, NEFA, and insulin. Total Ca and Mg were analyzed using an atomic absorption spectrophotometer (AAnalyst 200, Perkin-Elmer Inc., Waltham, MA) with the flame technique and acetylene gas as described previously (Martinez et al., 2012). Intra- and interassay CV were, respectively, 1.9 and $5.1 \%$ for $\mathrm{Ca}$, and 0.9 and $2.6 \%$ for Mg. Commercial kits were used for analyses of plasma concentrations of NEFA (NEFA-C kit; Wako Diagnostics Inc., Richmond, VA; as modified by Johnson and Peters, 1993) and BHBA (Wako Autokit 3-HB; Wako Diagnostics Inc.). Intra- and interassay CV were, respectively, 4.7 and $10.6 \%$ for NEFA, and 2.6 and $7.0 \%$ for BHBA. Insulin was analyzed using a commercial ELISA kit for bovine insulin (Mercodia Bovine Insulin
ELISA, Mercodia Inc., Uppsala, Sweden). Intra- and interassay CV were 3.3 and $8.7 \%$.

\section{Measurements of Cytosolic iCa ${ }^{2+}$ in Neutrophils and Lymphocytes}

Cytosolic concentrations of $\mathrm{iCa}^{2+}$ of isolated leukocytes were measured in vitro before and after stimulation with ionomycin at $0,24,48$, and $72 \mathrm{~h}$ after the beginning of infusion with a high-sensitivity, low-noise assay. Changes in $\mathrm{iCa}^{2+}$ concentration were recorded using a combined cellular loading with 2 nonratiometric Ca probes: Fura Red (Fura Red, AM, cell permeant, Life Technologies, Grand Island, NY) and Fluo-4 (Fluo-4, AM, cell permeant, Life Technologies), according to a protocol adapted from June et al. (2001). The ratio between Fluo-4 and Fura Red measures cytosolic $\mathrm{iCa}^{2+}$ and is more accurate than either probe by itself, because it controls for differences in cell size and cell loading (June et al., 2001).

For each sample, 2 extracellular media containing Hanks' balanced salt solution (HBSS) were used, one with $\mathrm{iCa}^{2+}$ concentration equivalent to that of normal cows $\left(1.26 \mathrm{mM} \mathrm{iCa}^{2+}\right)$ and one equivalent to cows with $\mathrm{SCH}\left(0.80 \mathrm{mMiCa}{ }^{2+}\right)$, to evaluate differences according to expected extracellular $\mathrm{iCa}^{2+}$ concentrations in $\mathrm{NC}$ and SCHI cows. Briefly, peripheral blood mononuclear cells (PBMC) and neutrophils were isolated by gradient density centrifugation using $6 \mathrm{~mL}$ of blood carefully overlaying $8 \mathrm{~mL}$ of Ficoll-Paque Premium 1077 (GE Healthcare, St. Giles, UK) and $8 \mathrm{~mL}$ of Histopaque 1119 (Sigma-Aldrich Co., St. Louis, MO), with the highest gradient at the bottom of the $50-\mathrm{mL}$ conical tubes. After $30 \mathrm{~min}$ of centrifugation at $2,000 \times \mathrm{g}$ and $21^{\circ} \mathrm{C}$, the entire granulocyte layer and $0.3 \mathrm{~mL}$ of the PBMC layer were separately transferred into 2 empty 50-mL vials, and each tube containing both cell types was then assigned to an HBSS medium containing 0.80 or $1.26 \mathrm{mM} \mathrm{iCa}^{2+}$ for the remainder of the assay. The tubes were washed with the respective medium and centrifuged at $1,400 \times g$ for $10 \mathrm{~min}$ at $21^{\circ} \mathrm{C}$. Supernatant was discarded and erythrocytes in the pellet were lysed using $20 \mathrm{~mL}$ of sterile distilled water, mixing gently for $20 \mathrm{~s}$, after which $5 \mathrm{~mL}$ of $5 \times$ PBS was added to restore isotonicity. Samples were centrifuged at $400 \times g$ for 5 min, the supernatant discarded, the lysis and centrifugation process repeated, and the pellet resuspended in $1 \mathrm{~mL}$ of the respective designated HBSS medium. The concentration of leukocytes was determined using a Coulter counter (Z Series Coulter counter, Beckman Coulter Inc., Brea, CA), samples were diluted to a final concentration of $4 \times 10^{6}$ cells $/ \mathrm{mL}$, and $1 \mathrm{~mL}$ of each sample was transferred into 5 -mL polystyrene tubes. 
Five microliters of Fluo- 4 and $12.5 \mu \mathrm{L}$ of Fura Red were added to $4 \times 10^{6}$ cells, samples were protected from light, and incubated at $37^{\circ} \mathrm{C}$ for $30 \mathrm{~min}$. Samples were then centrifuged at $180 \times g$ for $6 \mathrm{~min}$, and resuspended in their respective HBSS $\mathrm{iCa}^{2+}$ medium, incubated in the dark at room temperature for $15 \mathrm{~min}$, and then incubated at $37^{\circ} \mathrm{C}$ for $12 \mathrm{~min}$ before flow cytometric analysis. An Accuri C6 digital analyzer flow cytometer (Accuri C6, Becton Dickinson Immunocytometry Systems, San Jose, CA) was used for data acquisition. Fluo-4 and Fura Red emission were both excited using a 488-nm blue laser. Neutrophils and lymphocytes were then identified using forward and side scatter. The ratio of Fluo-4 to Fura Red in both cell populations was recorded for $1 \mathrm{~min}$ to obtain the prestimulation cytosolic $\mathrm{iCa}^{2+}$ ratio, and then for $10 \mathrm{~min}$ following the addition of the ionophore ionomycin at $1 \mathrm{~m} M$ concentration (Calbiochem, San Diego, CA) in the HBSS medium. The ionophore activates Ca channels in the endoplasmic reticulum, increasing cytosolic $\mathrm{iCa}^{2+}$ concentrations, and inducing a secondary sustained store operated $\mathrm{iCa}^{2+}$ entry. Kinetic data from acquisition of a least 300,000 cells detected in 11 min per sample were processed using FacsKin software (version 0.6.5, FacsKin, Budapest, Hungary; Kaposi et al., 2012). The prestimulation, post-maximum, and post-end ratios, as well as the area under the curve, were recorded for neutrophils and lymphocytes, using the same extracellular $\mathrm{iCa}^{2+}$ concentration that the cow had at the moment the sample was taken.

\section{Neutrophil Phagocytosis and Oxidative Burst}

The percentage of neutrophils exhibiting phagocytosis and oxidative burst activities after Escherichia coli challenge was measured in vitro at $0,24,48$, and $72 \mathrm{~h}$ after the beginning of infusion, according to procedures described in detail by Martinez et al. (2012). Briefly, whole blood was analyzed for total and differential cell counts using an automated hematology analyzer (ProCyte Dx Hematology Analyzer, Idexx Laboratories, Westbrook, ME). Neutrophils were loaded with dihydrorhodamine 123 (Sigma-Aldrich Co.) and then cocultured with propidium iodide-labeled $E$. coli isolated from milk from a cow with mastitis at a bacteria:neutrophil ratio of 40:1. The samples were run within $2 \mathrm{~h}$ of preparation using an Accuri C6 digital analyzer flow cytometer. Neutrophils were identified according to their size and granularity using forward and side scatter detectors, and data from acquisition of a least 10,000 cells per sample were analyzed using Flowjo software (version 7.6.5., Tree Star Inc., Ashland, OR). The parameters quantified were the percentage of neutrophils containing phagocytized propidium iodide- labeled E. coli, the percentage of neutrophils with oxidative burst activity, the mean fluorescence intensity (MFI) for phagocytosis as a proxy for the number of bacteria phagocytized per neutrophil, and the MFI for oxidative burst, as an indicator for the amount of oxygen reactive species generated per neutrophil.

\section{Statistical Analysis}

Data were analyzed using the GLIMMIX procedure of SAS (version 9.3, SAS Institute Inc., Cary, NC) for a crossover design. Distributions of the residuals of continuous data were evaluated for normality using graphical diagnostics, and data transformation was performed when appropriate. In the latter case, least squares means were back transformed and the standard errors of the means calculated. The Kenward-Roger method was used to calculate the denominator degrees of freedom to approximate the $F$-tests in the mixed models. Baseline measurements were calculated using the average of 1 or $2 \mathrm{~d}$ preceding the initiation of treatments, depending upon the response, and baseline measurements were included as covariate for the respective analysis.

For responses that required hourly measurements during the infusion period, 2 different analyses were performed to utilize the proper covariance structure according to sampling spacing, one during the 24-h infusion period, including hourly measurements, and another including measurements taken immediately after the infusion period and thereafter until $72 \mathrm{~h}$. The covariance structure that results in the lowest Akaike's information criterion was selected for each model.

Responses with repeated measures within the same cow for a given period were analyzed with models that included the covariate value, the fixed effect of treatment (NC, SCHI), block (1 to 5), period (1 and 2) nested within block, hour of measurement, and the interaction between treatment and hour. Random effects included cow nested within block and cow nested within treatment to account for the repeated measurements. Model fitting was evaluated using the fit statistics. When the $F$-test for an interaction was significant, means were then partitioned using the SLICE command in SAS. Treatment differences with $P \leq 0.05$ were considered significant, whereas tendencies for differences were reported if $0.05<P \leq 0.10$.

\section{RESULTS}

\section{Induction of Subclinical Hypocalcemia}

The rate of solution infused, adjusted hourly according to blood $\mathrm{iCa}^{2+}$ concentrations in SCHI cows and matched for the NC cow in the same block, averaged 
$8.57 \pm 0.41$ for the 24 -h infusion period, and ranged from 150 to $600 \mathrm{~mL} / \mathrm{h}$ for individual cows $(357 \pm 7.2 \mathrm{~mL} / \mathrm{h})$. Infusion of EGTA or saline solutions never stopped during the 24-h treatment period. As anticipated, the rate of infusion was exactly the same for both treatments. The amounts of solution infused resulted on an average of $1.13 \mathrm{~mol}$ of EGTA administered to SCHI cows (range $=0.74$ to $1.39 \mathrm{~mol} / \mathrm{cow}$ ).

All cows had blood $\mathrm{iCa}^{2+}>1.10 \mathrm{mM}$ before treatments were applied. As anticipated, infusion of $5 \%$ EGTA solution successfully induced $\mathrm{SCH}$ in SCHI cows (Figure 1a). All SCHI cows had blood $\mathrm{iCa}^{2+}<1$ $\mathrm{m} M$ within $2 \mathrm{~h}$ of infusion, and it remained $<1 \mathrm{~m} M$ in all cows for the next $24 \mathrm{~h}$ as all cows had blood $\mathrm{iCa}^{2+}<1 \mathrm{~m} M$ in the $2 \mathrm{~h}$ after cessation of infusion. The concentration of $\mathrm{iCa}^{2+}$ in blood remained lower $(P$ $<0.001)$ for SCHI than NC cows during the infusion period $\left(0.77 \pm 0.01\right.$ vs. $\left.1.26 \pm 0.01 \mathrm{mM} \mathrm{iCa}^{2+}\right)$ and only increased above $1.10 \mathrm{mM} 6 \mathrm{~h}$ after the end of infusion, at h 30 in the study. Similarly, total Ca concentration in plasma decreased in SCHI cows (1.74 \pm 0.03 vs. 2.07 $\pm 0.03 \mathrm{mM} \mathrm{Ca}$ ) during the infusion period (Figure 1b),
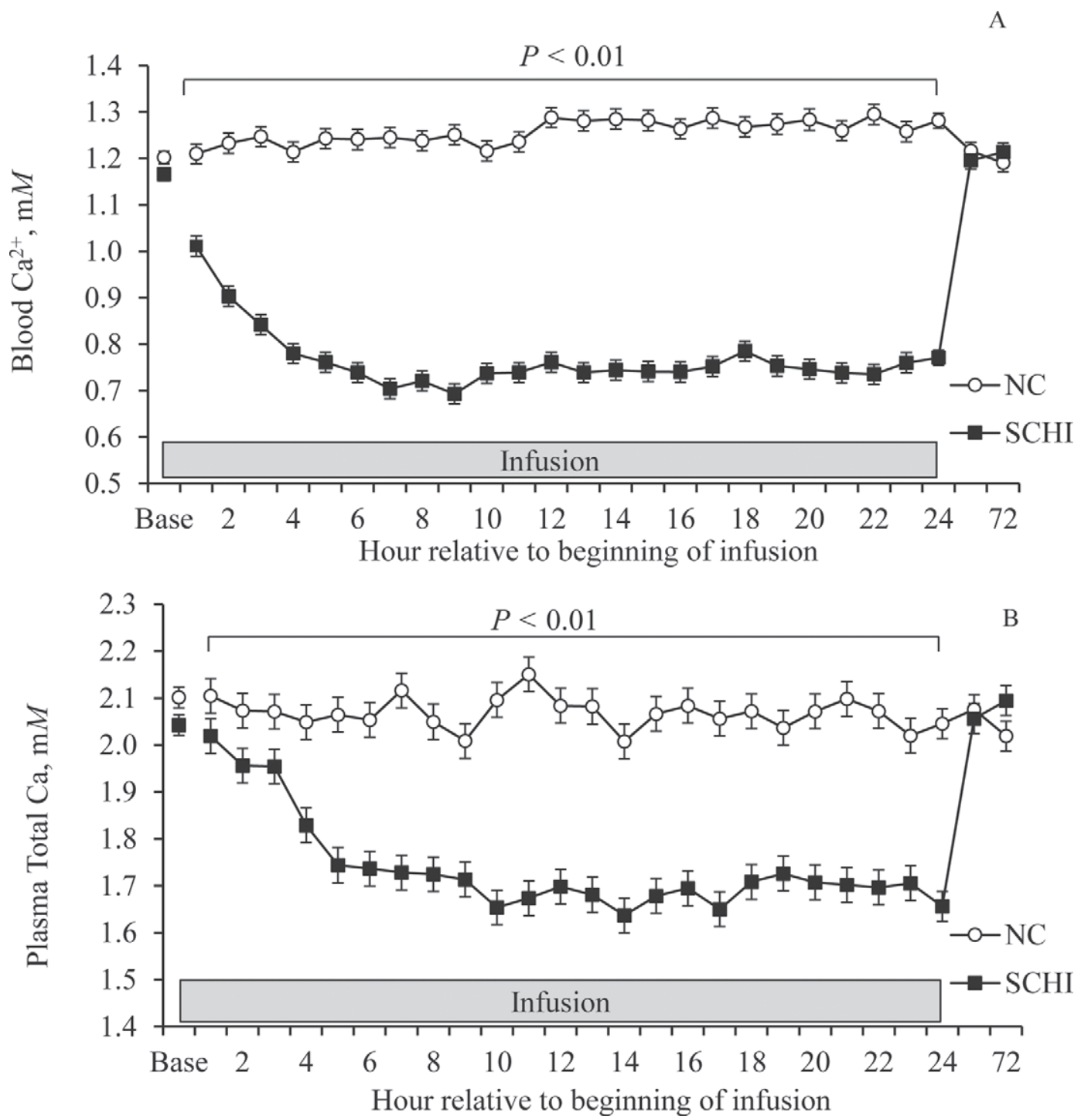

Figure 1. Calcium concentrations of cows subjected to normocalcemia (NC) or induced subclinical hypocalcemia (SCHI). Base $=$ mean of

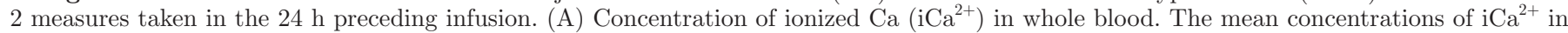
whole blood for the 72-h experimental period were $1.26 \pm 0.01$ and $0.77 \pm 0.01 \mathrm{~m} M$ for NC and SCHI, respectively. Statistical analysis revealed effects of treatment $(P<0.001)$, hour $(P<0.001)$, and interaction between treatment and hour $(P<0.001)$. (B) Concentration of total Ca in plasma. The mean concentrations of total $\mathrm{Ca}$ in plasma for the 72-h experimental period were $2.05 \pm 0.03$ and $1.94 \pm 0.03 \mathrm{mM}$ for $\mathrm{NC}$ and SCHI, respectively. Statistical analysis revealed effects of treatment $(P<0.001)$, hour $(P<0.001)$, and interaction between treatment and hour $(P<0.001)$. 


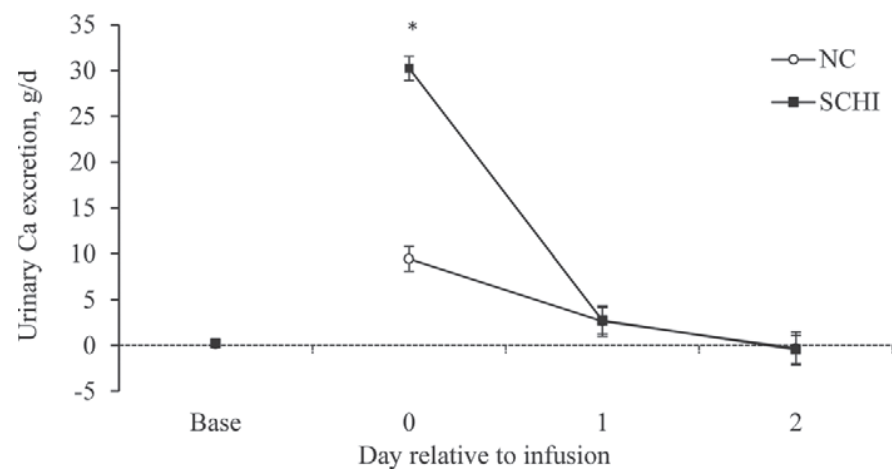

Figure 2. Urinary $\mathrm{Ca}$ excretion of cows subjected to normocalcemia $(\mathrm{NC})$ or induced subclinical hypocalcemia $(\mathrm{SCHI})$. Base $=$ mean of $\mathrm{d}-2$ and -1 relative to infusion. The mean daily urinary Ca excretions between $\mathrm{d} 0$ and 2 were $3.9 \pm 0.9$ and $10.8 \pm 0.8 \mathrm{~g} / \mathrm{d}$ for $\mathrm{NC}$ and SCHI, respectively. Statistical analysis revealed effects of treatment $(P$ $<0.001)$, day $(P<0.001)$, and interaction between treatment and day $(P<0.001) .{ }^{*}$ Within a day, treatments differ $(P<0.001)$.

but at a slower rate compared with blood $\mathrm{iCa}^{2+}$. In addition, the percentage of $\mathrm{iCa}^{2+}$ from total Ca decreased $(P<0.001)$ in SCHI compared with NC cows during the 24 -h infusion period ( $44.2 \pm 0.7$ vs. $61.0 \pm 0.7 \%$ of total $\mathrm{Ca})$.

\section{Urinary Excretion of $\mathrm{Ca}$}

Daily urinary volume was calculated based on the constant creatinine excretion of $29 \mathrm{mg} / \mathrm{kg}$ of BW (Valadares et al., 1999). We observed no difference $(P=$ 0.33 ) between SCHI and NC cows for the amount of urine produced $(14.6 \pm 1.4$ vs. $12.6 \pm 1.3 \mathrm{~L} / \mathrm{d})$ during the first $72 \mathrm{~h}$ of the study, and both groups had increased $(P<0.001)$ urinary output on the day of infusion $(18.2 \pm 1.8 \mathrm{~L} / \mathrm{d})$ compared with the day before infusion $(10.1 \pm 1.5 \mathrm{~L} / \mathrm{d})$. Urinary excretion of $\mathrm{Ca}$ increased in both treatments on the day of infusion and was greater $(P<0.001)$ for SCHI compared with NC cows $(30.2 \pm 1.3$ vs. $9.4 \pm 1.3 \mathrm{~g} / \mathrm{d})$ on that day (Figure 2). Therefore, induction of SCH with 5\% EGTA chelated approximately $30 \mathrm{~g}$ of $\mathrm{Ca}$ on the day of the infusion, based on the difference between urinary excretion of $\mathrm{Ca}$ on the day of infusion compared with that observed on the day preceding infusion, which averaged $0.21 \pm$ $0.04 \mathrm{~g} / \mathrm{d}$. This amount of Ca chelated and excreted is similar to that secreted in colostrum when cows initiate lactation (Horst et al., 2005).

\section{DMI and Physiological Responses}

The DMI of cows decreased $(P<0.001)$ on the day of infusion and was lower $(P<0.01)$ for SCHI compared with $\mathrm{NC}$ cows $(5.3 \pm 0.8$ vs. $9.1 \pm 0.8 \mathrm{~kg} / \mathrm{d}$; Figure $3)$. Cows in both treatments recovered their DMI on the day following treatment to an amount comparable

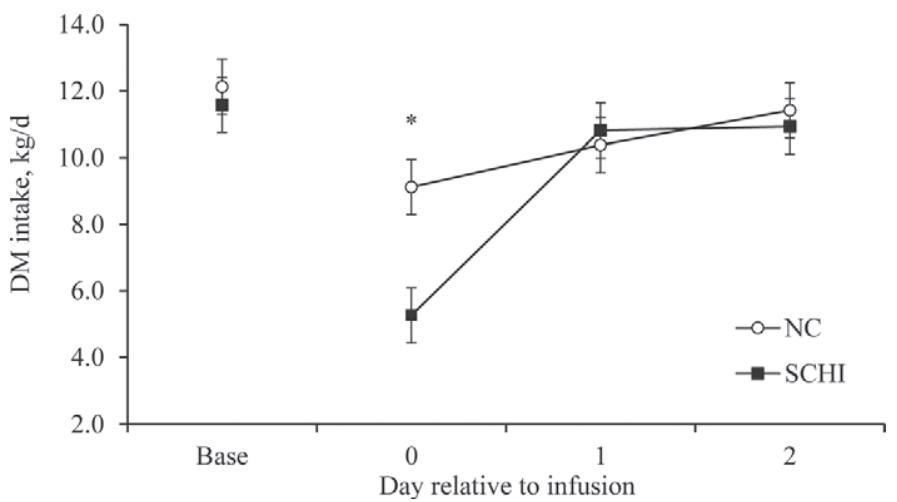

Figure 3. Dry matter intake of cows subjected to normocalcemia $(\mathrm{NC})$ or induced subclinical hypocalcemia $(\mathrm{SCHI})$. Base $=$ mean of $\mathrm{d}-2$ and -1 relative to infusion. The mean DMI between $\mathrm{d} 0$ and 2 were $10.3 \pm 0.6$ and $9.0 \pm 0.6 \mathrm{~kg} / \mathrm{d}$ for $\mathrm{NC}$ and SCHI, respectively. Statistical analysis revealed effects of treatment $(P=0.15)$, day $(P$ $<0.001)$, and interaction between treatment and day $(P=0.02)$. *Within a day, treatments differ $(P<0.01)$.

to the pretreatment intakes. Induction of subclinical hypocalcemia reduced $(P=0.01)$ the number of rumen contractions $(1.9 \pm 0.2$ vs. $2.7 \pm 0.2$ contractions $/ 2$ min) during the second half of the infusion period.

Respiration and heart rates and vaginal temperature were not affected by treatment (Table 2). Cows in both treatments had a decrease in urine $\mathrm{pH}$, with a nadir at $24 \mathrm{~h}$ after beginning of infusion. However, urine $\mathrm{pH}$ was less $(P=0.001)$ for cows with SCHI at $12 \mathrm{~h}$ of the infusion period $(\mathrm{pH} 6.2 \pm 0.3$ vs. $\mathrm{pH} 7.6 \pm 0.3)$ compared with $\mathrm{NC}$ cows, after which no differences were detected.

\section{Blood pH, Minerals, Metabolites, and Hormones}

Blood $\mathrm{pH}$ declined $(P<0.01)$ in both treatments from an average of $7.428 \pm 0.008$ at $0 \mathrm{~h}$ to $7.391 \pm$ 0.007 within $1 \mathrm{~h}$ of infusion. For the first $13 \mathrm{~h}$ of infusion, blood $\mathrm{pH}$ was not different between treatments and averaged $7.387 \pm 0.007$. However, cows with $\mathrm{NC}$ had a further decrease $(P=0.04)$ in $\mathrm{pH}$ in the last $11 \mathrm{~h}$ of infusion and remained lower until $72 \mathrm{~h}$ in the study, averaging $7.377 \pm 0.004$ and $7.392 \pm 0.004$ for $\mathrm{NC}$ and $\mathrm{SCHI}$, respectively. The further decline in $\mathrm{pH}$ for $\mathrm{NC}$ coincided with the administration of the second bolus of $\mathrm{Ca}$ at $\mathrm{h} 11$. Blood $\mathrm{pH}$ returned to baseline values in both treatments within $48 \mathrm{~h}$ after the end of the infusions. Similar to blood $\mathrm{pH}$, blood $\mathrm{HCO}_{3}{ }^{-}$did not differ between NC and SCHI before treatments $(27.2$ $\pm 0.6 \mathrm{mM})$, but decreased $(P<0.01)$ within $1 \mathrm{~h}$ of infusion in both treatments. During the 24 -h infusion, blood $\mathrm{HCO}_{3}{ }^{-}$averaged $22.0 \pm 0.7$ and $22.2 \pm 0.7 \mathrm{mM}$ for NC and SCHI, respectively. Bicarbonate concentrations quickly returned to baseline within the first $24 \mathrm{~h}$ after the end of the infusion. 
Table 2. Effect of inducing subclinical hypocalcemia on physiological measures of dairy cows in the first 72 $\mathrm{h}$ after treatment

\begin{tabular}{|c|c|c|c|c|c|}
\hline \multirow[b]{2}{*}{ Item } & \multicolumn{2}{|c|}{ Treatment $^{1}$} & \multicolumn{3}{|c|}{$P$-value ${ }^{2}$} \\
\hline & $\mathrm{NC}$ & SCHI & Trt & Hour & Trt $\times$ Hour \\
\hline Respiration rate, no./min & $43.7 \pm 1.1$ & $42.5 \pm 1.1$ & 0.38 & 0.20 & 0.96 \\
\hline Heart rate, no./min & $68.7 \pm 1.1$ & $68.8 \pm 1.1$ & 0.98 & 0.02 & 0.87 \\
\hline Vaginal temperature, ${ }^{\circ} \mathrm{C}$ & $38.9 \pm 0.1$ & $38.8 \pm 0.1$ & 0.70 & $<0.01$ & 0.74 \\
\hline
\end{tabular}

${ }^{1} \mathrm{NC}=$ normocalcemia (i.v. infusion of $0.9 \% \mathrm{NaCl} 24 \mathrm{~h}$ plus $43 \mathrm{~g}$ of oral $\mathrm{Ca}$, as Ca sulfate and Ca chloride, at -1 and $11 \mathrm{~h}$ ); SCHI = induced subclinical hypocalcemia (i.v. infusion of $5 \%$ ethylene glycol tetraacetic acid solution for $24 \mathrm{~h}$ to maintain blood $\mathrm{iCa}^{2+}<1.0 \mathrm{~m} M$, without recumbency).

${ }^{2}$ Trt $=$ effect of treatment; Trt $\times$ hour $=$ interaction between Trt and hour after the beginning of infusion.

Concentrations of $\mathrm{K}$ in blood were less $(P<0.001)$ for SCHI compared with NC cows during the 24-h infusion period $(2.91 \pm 0.04$ vs. $3.48 \pm 0.04 \mathrm{mM})$ but returned to baseline within the first $24 \mathrm{~h}$ after the end of the infusion. Concentrations of $\mathrm{Mg}$ in plasma increased $(P<0.001)$ during infusion in SCHI cows compared with $\mathrm{NC}$ cows and averaged $0.93 \pm 0.01$ and $0.67 \pm$ $0.01 \mathrm{~m} M$, respectively.

Interestingly, cows with SCHI had greater $(P<0.01)$ blood glucose concentrations than $\mathrm{NC}$ cows throughout the infusion period $(4.40 \pm 0.04$ vs. $4.17 \pm 0.04 \mathrm{mM}$; Figure 4). In addition, cows subjected to SCHI had reduced $(P<0.01)$ concentrations of insulin in plasma between 6 and $18 \mathrm{~h}$ after the beginning of the infusion $(1.44 \pm 0.23$ vs. $2.32 \pm 0.23 \mathrm{ng} / \mathrm{mL}$; Figure 5$)$. Concurrently, plasma concentrations of NEFA increased $(P<$ $0.05)$ compared with $\mathrm{NC}$ cows $(0.110 \pm 0.02$ vs. 0.061 $\pm 0.01 \mathrm{mM}$; Figure 6). Finally, concentrations of BHBA in plasma did not differ $(P=0.56)$ between SCHI and $\mathrm{NC}$ cows and averaged $0.374 \pm 0.13$ and $0.357 \pm 0.13$ $\mathrm{m} M$, respectively.

\section{Complete Blood Cell Count and Neutrophil Function}

The number of erythrocytes, platelets, and total leukocytes per milliliter of blood did not differ between SCHI and NC cows. Similarly, the differential leukocyte count was not affected by treatment, and SCHI and NC had similar numbers of lymphocytes and neutrophils. However, SCHI cows had a tendency for increased number of monocytes per milliliter of blood (Table 3).

Neutrophil function was suppressed by SCH. Cows induced to develop SCH had a reduced $(P=0.01)$ percentage of neutrophils with phagocytic activity (22.1 \pm 2.1 vs. $29.3 \pm 2.1 \%$; Figure $7 \mathrm{a})$, with similar $(P=$ $0.46)$ numbers of bacteria phagocytized per neutrophil between SCHI and $\mathrm{NC}$ cows $(78,842 \pm 1,927$ vs. 80,975 $\pm 1,979$ MFI, respectively). Furthermore, SCHI cows had a reduction $(P<0.01)$ in the percentage of neutrophils with oxidative burst activity $(16.1 \pm 1.7$ vs. $24.2 \pm 1.7 \%$; Figure $7 \mathrm{~b})$, with lower $(P<0.01)$ production of reactive oxygen species per neutrophil $(54,778$ $\pm 2,403$ vs. $65,552 \pm 2,237 \mathrm{MFI})$ compared with $\mathrm{NC}$

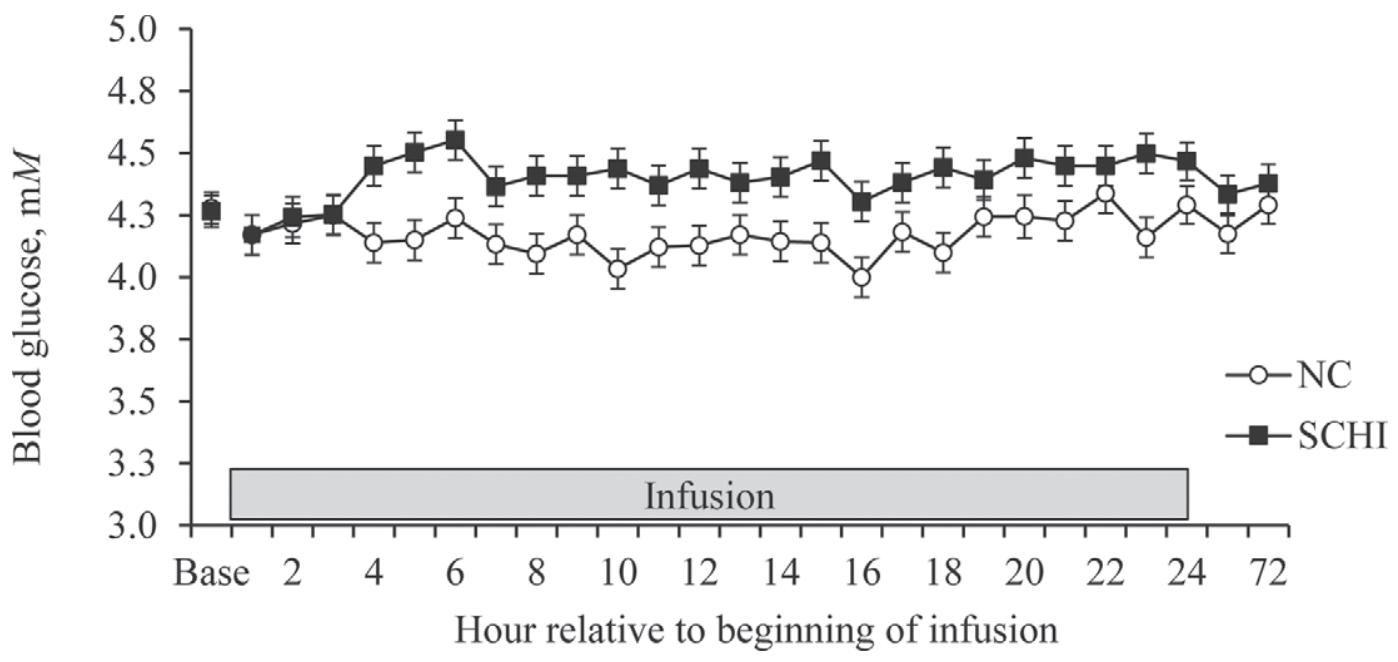

Figure 4. Blood glucose concentrations of cows subjected to normocalcemia $(\mathrm{NC})$ or induced subclinical hypocalcemia $(\mathrm{SCHI})$. Base $=$ mean of 2 measurements taken in the $24 \mathrm{~h}$ preceding infusion. The mean concentrations of whole-blood glucose during the 24 -h infusion were 4.17 \pm 0.04 and $4.40 \pm 0.04 \mathrm{~m} M$ for NC and SCHI, respectively. Statistical analysis revealed effects of treatment $(P=0.01)$, hour $(P=0.11)$, and interaction between treatment and hour $(P=0.25)$. 


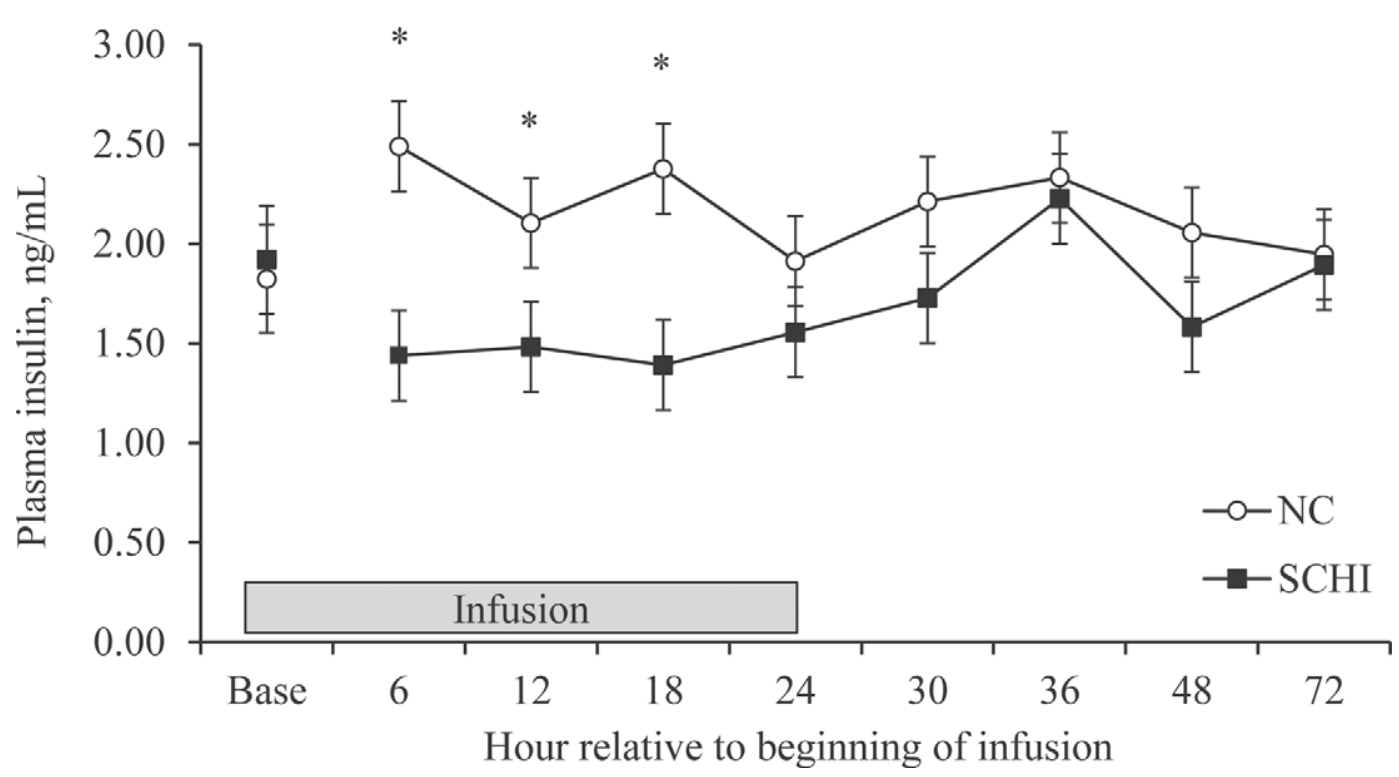

Figure 5. Plasma insulin concentrations of cows subjected to normocalcemia $(\mathrm{NC})$ or induced subclinical hypocalcemia $(\mathrm{SCHI})$. Base $=$ mean of 2 measurements taken in the $24 \mathrm{~h}$ preceding infusion. The mean values for plasma insulin for the 72-h experimental period were $2.18 \pm$ 0.17 and $1.66 \pm 0.17 \mathrm{ng} / \mathrm{mL}$ for NC and SCHI, respectively. Statistical analysis revealed effects of treatment $(P=0.06)$, hour $(P=0.05)$, and interaction between treatment and hour $(P<0.05)$. ${ }^{*}$ Within an hour, treatments differ $(P=0.02)$.

cows. In fact, relative to the baseline values at $\mathrm{h} 0$, both phagocytosis and oxidative burst declined $(P<0.05)$ in SCHI $(73.7 \pm 18.2 \%$ and $69.4 \pm 20.4 \%$ for phagocytosis and oxidative burst), whereas both increased in $\mathrm{NC}$ cows $(127.8 \pm 18.2$ and $160.6 \pm 20.4 \%$ for phagocytosis and oxidative burst) at $72 \mathrm{~h}$ after the beginning of the infusion.

\section{Cytosolic Measurements of iCa $^{2+}$ in Neutrophils and Lymphocytes}

For neutrophils, SCHI and NC cows had similar $(P$ $>0.30$ ) amounts of cytosolic $\mathrm{iCa}^{2+}$ before stimulation $(2.0 \pm 0.2$ vs. $2.2 \pm 0.2$ Fluo-4:Fura Red prestimulation ratio $)$ and at the peak $(16.6 \pm 1.4$ vs. $18.8 \pm 1.4$ Fluo-

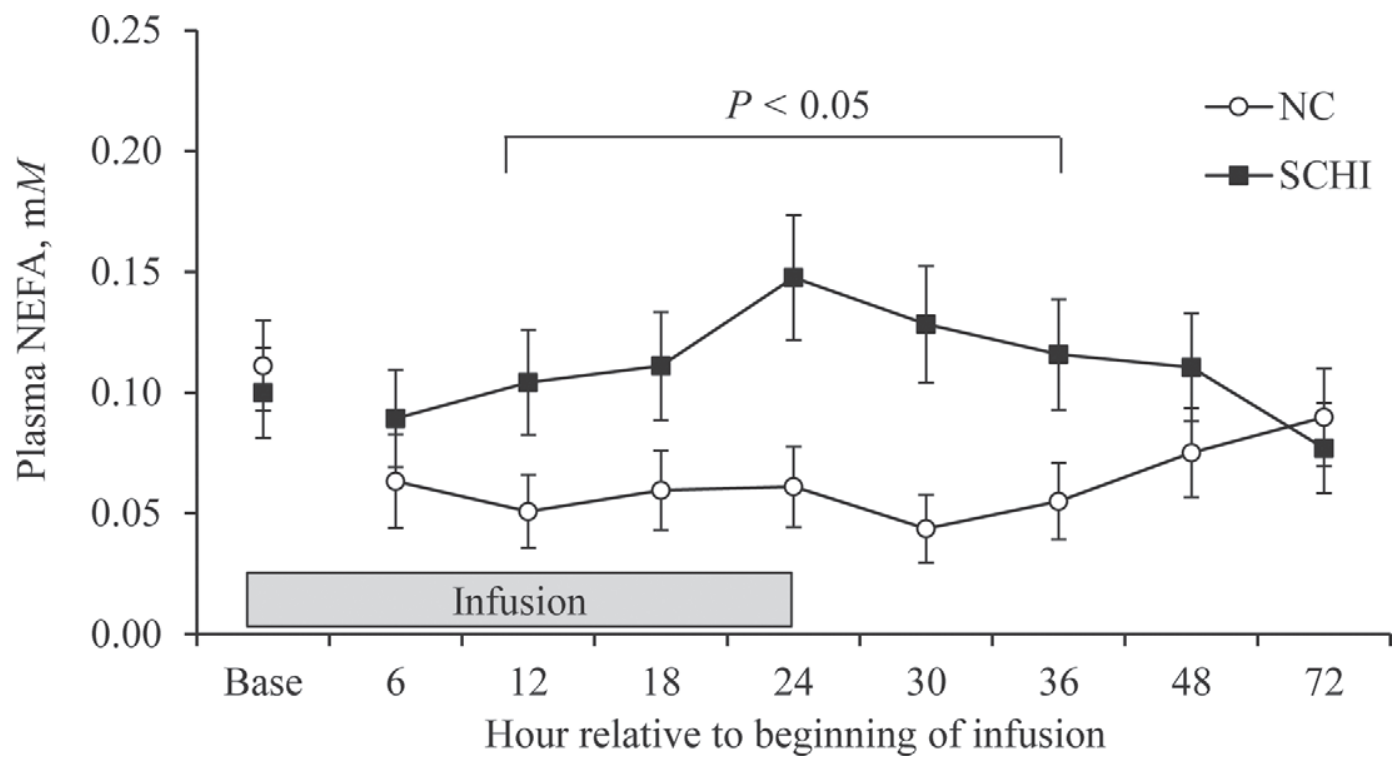

Figure 6. Plasma NEFA concentrations of cows subjected to normocalcemia $(\mathrm{NC})$ or induced subclinical hypocalcemia $(\mathrm{SCHI})$. Base $=$ mean of 2 measurements taken in the $24 \mathrm{~h}$ preceding infusion. The mean concentrations of plasma NEFA during the 24-h infusion were 0.061 \pm 0.01 and $0.110 \pm 0.02 \mathrm{mM}$ for NC and SCHI, respectively. Statistical analysis revealed effects of treatment $(P=0.02)$, hour $(P<0.74)$, and interaction between treatment and hour $(P=0.11)$. 
Table 3. Effect of inducing subclinical hypocalcemia on counts of erythrocytes, leukocytes, and platelets in blood of dairy cows in the first $72 \mathrm{~h}$ after treatment

\begin{tabular}{|c|c|c|c|c|c|}
\hline \multirow[b]{2}{*}{ Item } & \multicolumn{2}{|c|}{ Treatment $^{1}$} & \multicolumn{3}{|c|}{$P$-value ${ }^{2}$} \\
\hline & $\mathrm{NC}$ & SCHI & Trt & Hour & Trt $\times$ Hour \\
\hline Erythrocytes, $10^{6} / \mu \mathrm{L}$ & $6.09 \pm 0.23$ & $6.04 \pm 0.23$ & 0.61 & 0.61 & 0.53 \\
\hline Platelets, $10^{3} / \mu \mathrm{L}$ & $286.1 \pm 20.4$ & $284.0 \pm 20.4$ & 0.95 & 0.03 & 0.97 \\
\hline Leukocytes, $10^{3} / \mu \mathrm{L}$ & $15.34 \pm 0.68$ & $14.85 \pm 0.68$ & 0.58 & 0.02 & 0.80 \\
\hline Lymphocytes, $10^{3} / \mu \mathrm{L}$ & $10.48 \pm 0.40$ & $10.06 \pm 0.40$ & 0.31 & 0.09 & 0.46 \\
\hline Neutrophils, $10^{3} / \mu \mathrm{L}$ & $3.16 \pm 0.34$ & $2.52 \pm 0.34$ & 0.20 & 0.08 & 0.92 \\
\hline Monocytes, $10^{3} / \mu \mathrm{L}$ & $1.21 \pm 0.17$ & $1.73 \pm 0.17$ & 0.08 & 0.89 & 0.33 \\
\hline
\end{tabular}

4:Fura Red post-maximum ratio) after stimulation with ionomycin (Figure 8). However, cows with SCHI had less $(P=0.05)$ cytosolic $\mathrm{iCa}^{2+}$ during the post-end phase of the assay $(9.9 \pm 1.0$ vs. $13.6 \pm 1.4$ Fluo- 4 :Fura Red post-end ratio), which typically characterizes entry of $\mathrm{iCa}^{2+}$ from the extracellular space. Indeed, the SCHI cows tended $(P=0.07)$ to have a faster decline in cytosolic concentrations of $\mathrm{iCa}^{2+}$ after the post-maximum ratio based on the difference between measurements taken at the post-maximum and post-end phases of the assay compared with $\mathrm{NC}$ cows $(-4.7 \pm 0.5$ vs. $-3.3 \pm$ 0.5 Fluo-4:Fura Red ratio decline). As a result of less cytosolic $\mathrm{iCa}^{2+}$, the area under the curve for all phases of the assay tended $(P=0.08)$ to be smaller in SCHI compared with $\mathrm{NC}$ cows $(5,382 \pm 910$ vs. $7,013 \pm 702$ relative intensity units/s).

The amount of cytosolic $\mathrm{iCa}^{2+}$ in lymphocytes did not differ $(P>0.26)$ between SCHI and NC cows before $(0.23 \pm 0.1$ vs. $0.39 \pm 0.1$ Fluo-4:Fura Red pre-stimulation ratio), at the peak concentration (25.3 \pm 1.6 vs. $27.4 \pm 1.7$ Fluo-4:Fura Red post-maximum ratio), and at the end of the measurement period (20.8 \pm 1.7 vs. $22.8 \pm 1.7$ Fluo-4:Fura Red post-end ratio). Similarly, no differences were found in the area under the curve $(11,166 \pm 734$ vs. $12,520 \pm 855$ relative intensity units/s) between SCHI and NC cows.

\section{DISCUSSION}

Continuous infusion of a solution containing 5\% EGTA successfully induced SCH in all SCHI cows within $2 \mathrm{~h}$, which compromised DMI and rumen contractions, altered insulin concentrations, increased lipolysis, and decreased cellular replenishment of cytosolic $\mathrm{iCa}^{2+}$ in neutrophils, thereby suppressing phagocytosis and bacterial killing.

The onset of lactation is accompanied by a state of negative nutrient balance and immune dysfunction, and the severity and duration of these conditions render cows susceptible to infectious diseases and metabolic disorders (Sordillo and Raphael, 2013). Subclinical hypocalcemia has been associated with disturbances in measures of energy metabolism and reduced immune function (Larsen et al., 2001; Martinez et al., 2012), which has been linked to increased risk of peripartum
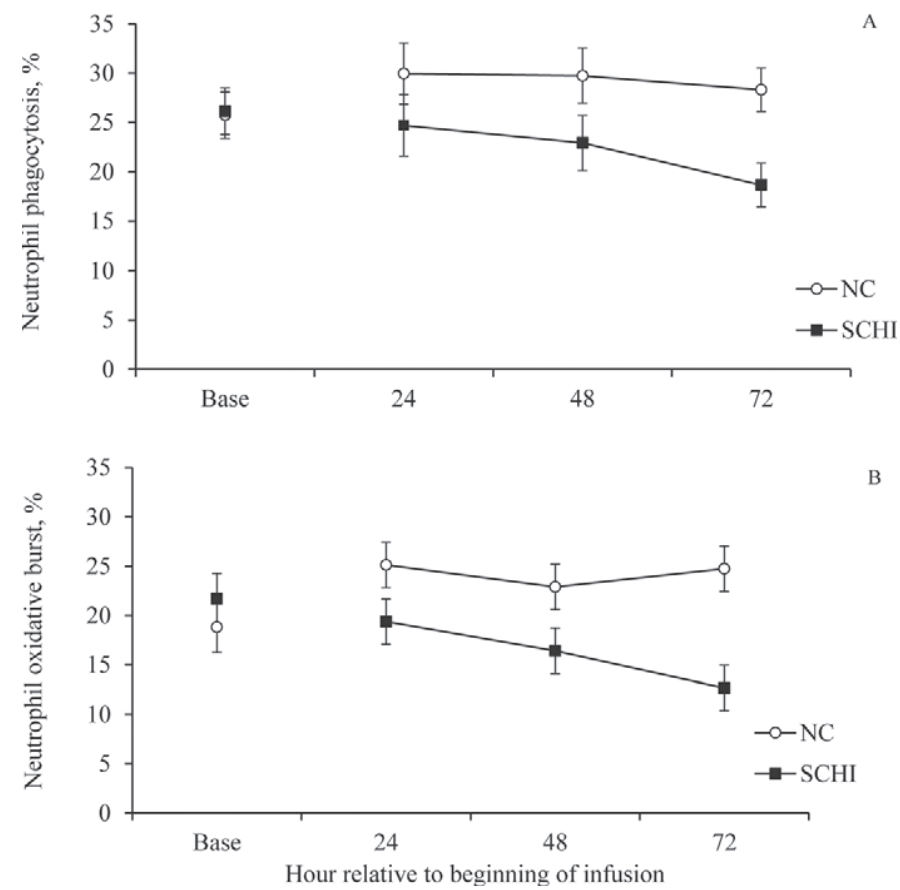

Figure 7. Neutrophil function of cows subjected to normocalcemia (NC) or induced subclinical hypocalcemia (SCHI). Baseline refers to phagocytosis at hour -0.5 , before treatments were applied. (A) Phagocytosis of Escherichia coli; mean phagocytosis in the $72 \mathrm{~h}$ following treatments were $29.3 \pm 2.1$ and $22.1 \pm 2.1 \%$ for $\mathrm{NC}$ and SCHI cows, respectively. Statistical analysis revealed effects of treatment $(P$ $=0.01)$, hour $(P=0.17)$, and interaction between treatment and hour $(P=0.58)$. (B) Oxidative burst; mean oxidative burst in the $72 \mathrm{~h}$ following treatments were $24.2 \pm 1.7$ and $16.1 \pm 1.7 \%$ for $\mathrm{NC}$ and $\mathrm{SCHI}$ cows, respectively. Statistical analysis revealed effects of treatment $(P$ $<0.01)$, hour $(P=0.23)$, and interaction between treatment and hour $(P=0.25)$. 


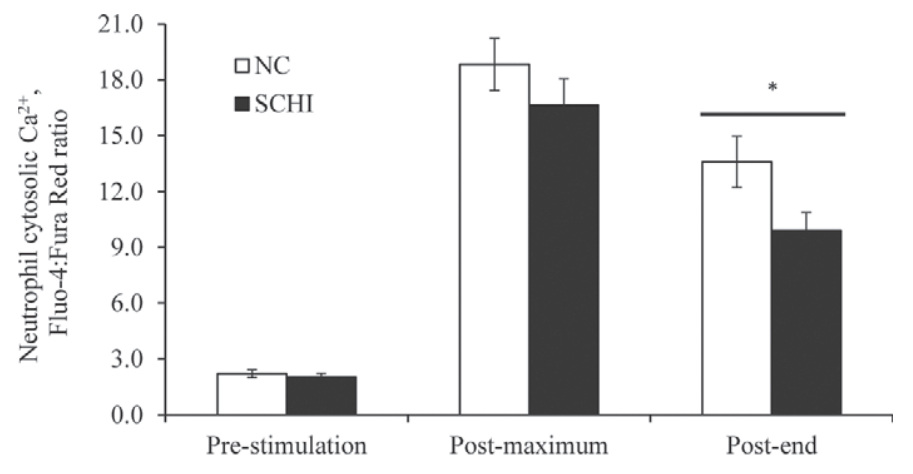

Stage relative to ionophore stimulation

Figure 8. Neutrophil cytosolic ionized $\mathrm{Ca}\left(\mathrm{iCa}^{2+}\right)$ of cows subjected to normocalcemia (NC) or induced subclinical hypocalcemia (SCHI). For the prestimulation stage, effects of treatment $(P=0.54)$, hour $(P=0.07)$, and interaction between treatment and hour $(P=$ $0.84)$. For the post-maximum ratio after ionophore stimulation, statistical analysis revealed effects of treatment $(P=0.30)$, hour $(P=$ $0.07)$, and interaction between treatment and hour $(P=0.92)$. For the post-end ratio, statistical analysis revealed effects of treatment $(P=$ $0.05)$, hour $(P=0.06)$, and interaction between treatment and hour $(P=0.71) .{ }^{*}$ Treatments differ $(P<0.05)$.

diseases (Martinez et al., 2012). Because of the high prevalence of $\mathrm{SCH}$ in the first week of lactation (Reinhardt et al., 2011) and the high incidence of peripartum problems in dairy cows, it is important to document and understand the effects of subnormal concentrations of $\mathrm{iCa}^{2+}$ on energy metabolism and immune function. These findings support some of the results obtained in a previous epidemiological study in early postpartum dairy cows (Martinez et al., 2012) and corroborate the idea of a direct mechanism by which $\mathrm{SCH}$ further depresses energy balance and innate immune function in early postpartum dairy cows.

The rationale for using nonpregnant, nonlactating dairy cows as a model to induce $\mathrm{SCH}$ was to isolate effects inherently related to SCHI, therefore avoiding the typical hormonal and metabolic adaptations that occur with parturition and the onset of lactation in dairy cows. Nevertheless, the amount of $\mathrm{iCa}^{2+}$ chelated by EGTA, based on increased urinary excretion during the day of infusion, was equivalent to the amount of Ca secreted in colostrum on the day of calving in dairy cows (Horst et al., 2005). This indicates that the model utilized in SCHI cows resulted in an average daily loss of $\mathrm{iCa}^{2+}$ similar to that of early postpartum dairy cows after the first milking postpartum. The amount of EGTA infused per cows averaged 1.13 mol, which is sufficient to chelate approximately $45 \mathrm{~g}$ of $\mathrm{iCa}^{2+}$, based on the chelating ability of a 1:1 molar ratio of EGTA and $\mathrm{iCa}^{2+}$. Therefore, the average amount of $\mathrm{Ca}$ excreted in the urine of SCHI cows on the day of infusion, although high (30.2 g), represented only
$67.1 \%$ of the potential chelating ability of the EGTA administered.

The first hypothesis of the study was that cows with SCHI would have decreased DMI compared with $\mathrm{NC}$ cows. Infusion of either saline or EGTA solutions reduced DMI, but the magnitude of decline doubled in SCHI compared with controls. Induction of $\mathrm{SCH}$ suppressed DMI when blood $\mathrm{iCa}^{2+}$ was low, but appetite quickly recovered as concentrations of $\mathrm{iCa}^{2+}$ were reestablished in the subsequent days. Subclinical hypocalcemia reduces rumen contractions, thereby affecting rumination and particulate matter passage rate, which might influence rumen fill. In lactating and dry cows, diets with excessive content of NDF are known to suppress appetite by increasing rumen fill because of a reduced rate of digestion (Allen, 2000). However, given the relatively low dietary NDF of the diet fed to dry cows, it is unlikely that rumen fill was a major factor for the reduced intake. Others have observed a reduction in chewing activity and smooth muscle contractility of rumen and abomasum in cows with induced subclinical or clinical hypocalcemia (Daniel, 1983; Hansen et al., 2003). Perhaps an overall reduction in digestive tract motility, which likely affected the forestomachs but also the abomasum and intestine, reduced appetite independently of pressure sensors typically activated during distension of the gut (Allen, 2000).

The second hypothesis of the study was that cows with SCHI would have increased NEFA and BHBA compared with NC cows. The animals used in the present study were nonpregnant, nonlactating dairy cows and, even though these cows were not under negative caloric balance at the time of $\mathrm{SCH}$ induction, SCHI cows exhibited an increased concentration of NEFA in plasma compared with NC cows. This finding agrees with results of previous studies in early lactating dairy cows in which the typical elevation in plasma concentrations of NEFA and BHBA in blood were exacerbated in cows diagnosed with $\mathrm{SCH}$ (Martinez et al., 2012; Ribeiro et al., 2013). However, the results of the present study with dry cows did not indicate an effect of SCHI on concentrations of BHBA in plasma. The latter is likely related to the relatively low baseline $(0.100 \pm 0.02 \mathrm{mM})$ NEFA concentrations in SCHI cows, and because BHBA typically increases when hepatic uptake of NEFA exceeds the energy requirements of the hepatocytes (Fukao et al., 2004). It is possible that even after the concentrations of NEFA in plasma of SCHI increased by $50 \%$ at the end of the EGTA infusion period $(0.148 \pm 0.03 \mathrm{mM})$, the amounts of NEFA taken up by the liver and oxidized were still below the concentrations necessary to overwhelm hepatocytes and stimulate an increased production of ketone bodies 
by diverting fatty acid carbon from complete oxidation to ketogenesis.

Interestingly, cows with SCHI had an immediate and constant elevation in whole-blood glucose concentrations compared with $\mathrm{NC}$ throughout the infusion day, concurrently with a decreased in insulin concentrations in plasma. An increase in blood glucose can be attributed to a decrease in insulin production with a corresponding decrease in circulating insulin (Hayirli, 2006). Spontaneous hypocalcemia is known to impair insulin release in dairy cows with milk fever (Littledike et al., 1968). In addition, experiments with different animal species and in vitro with human $\beta$ cells demonstrated that the pancreatic cells require $\mathrm{iCa}^{2+}$ influx into the cytosol to release insulin granules and to respond to insulin after glucose tolerance tests (Witzel and Littledike, 1973; Rorsman et al., 2012). This could explain the lower concentrations of insulin in plasma observed in SCHI compared with NC cows. Collectively, these results suggest that SCHI impaired pancreatic insulin secretion, which in turn increased glucose concentrations in blood by reducing peripheral tissue glucose uptake. The increase in glucose concentration observed in SCHI cows is consistent with a study that evaluated chemical profiles in cows within $12 \mathrm{~h}$ of calving, finding a negative correlation between blood glucose and total blood Ca (Larsen et al., 2001). Another consequence of decreased insulin secretion is the removal of the inhibition of hormone sensitive lipase, which promotes lipolysis, thus increasing lipid mobilization and, ultimately, NEFA concentrations in blood (Fukao et al., 2004). Such changes in plasma insulin likely explain the elevation in plasma NEFA observed in the present study. These results have important implications for early lactation cows that typically develop insulin resistance (Hayirli, 2006). Further impairment in insulin and glucose metabolism might increase lipolytic signals and promote additional tissue catabolism, thus predisposing cows to lipid-related disorders. Indeed, hypocalcemia has been linked to increased risk of ketosis in dairy cows (Curtis et al., 1983).

The main hypothesis of the study was that immune cells of SCHI cows would have less cytosolic $\mathrm{iCa}^{2+}$ available for activation and, as a consequence, function would be affected. The association between decreased neutrophil function and SCH (Martinez et al., 2012) or clinical hypocalcemia (Ducusin et al., 2003) has been reported before. Cows with milk fever have been shown to have reduced cytosolic concentrations of $\mathrm{iCa}^{2+}$ in PBMC, which has been suggested to impair immune function (Kimura et al., 2006). The theory underlying the hypothesis is that upon engagement of immune cell antigen receptor with an antigen, a signaling cascade is activated, resulting in an increase in cytosolic $\mathrm{iCa}^{2+}$ and depletion of $\mathrm{iCa}^{2+}$ stores from the endoplasmic reticulum (Bréchard and Tschirhart, 2008). The depletion of endoplasmic reticulum $\mathrm{iCa}^{2+}$ stores is soon followed by activation of store-operated $\mathrm{iCa}^{2+}$ entry, which induces an additional influx of $\mathrm{iCa}^{2+}$ from the extracellular space, generating a transient peak (Bréchard and Tschirhart, 2008). The final replenishment of $\mathrm{iCa}^{2+}$ is regulated by activation of the sarcoplasmic and endoplasmic reticulum $\mathrm{iCa}^{2+}$ ATPase pumps, which allows for $\mathrm{iCa}^{2+}$ entry from the cytosol into the endoplasmic reticulum (Burgos et al., 2011). Lack of adequate concentrations of extracellular $\mathrm{iCa}^{2+}$ are expected to decrease the entry of $\mathrm{iCa}^{2+}$ through store-operated $\mathrm{iCa}^{2+}$ channels, which would compromise cell organelle replenishment of $\mathrm{Ca}$ concentrations. Additionally, not only is the $\mathrm{iCa}^{2+}$ increase required for the initiation of multiple immune cell functions, but also the dynamics of magnitude, amplitude, and duration of changes in cytosolic $\mathrm{iCa}^{2+}$ control the destiny of the immune cells (Quah and Parish, 2012).

In this study, after inducing activation of neutrophils, the levels of cytosolic $\mathrm{iCa}^{2+}$ declined faster in SCHI cows than in NC cows. Therefore, the results indicate that the influx of extracellular $\mathrm{iCa}^{2+}$ was unable to sustain the use of cytosolic $\mathrm{iCa}^{2+}$, or to replenish the endoplasmic reticulum stores, or both. An increase in cytosolic $\mathrm{iCa}^{2+}$ is required to trigger adhesion to endothelial cells, migration, phagocytosis, and killing in neutrophils (Cohen, 1994). Therefore, it is plausible that the observed reduction in cytosolic $\mathrm{iCa}^{2+}$ replenishment explains the reduced phagocytic and killing activities of neutrophil in SCHI cows. The negative effects on neutrophil function persisted for $72 \mathrm{~h}$ after the end of infusion with EGTA, even though the extracellular $\mathrm{iCa}^{2+}$ concentrations returned to baseline at $30 \mathrm{~h}$ in the study. It is known that the mature bovine neutrophil is stored in the bone marrow until released into the circulation, where it remains an average of $9 \mathrm{~h}$ before mobilizing into organs to undergo apoptosis (Paape et al., 2003). Hence, these results suggest that SCHI cows had not only mature circulating neutrophils affected, but also those stored in the bone marrow or undergoing final maturation.

In contrast to the findings in neutrophils, no statistical differences were detected for the concentrations of cytosolic $\mathrm{iCa}^{2+}$ in lymphocytes between SCHI and NC cows at different stages of induced activation, although they were numerically less for SCHI. These results disagree from those of others (Kimura et al., 2006), who observed a decline in PBMC cytosolic $\mathrm{iCa}^{2+}$ in cows with milk fever. Recently calved cows with milk fever are expected to have much less circulating $\mathrm{iCa}^{2+}$ than dry cows with SCHI, which likely explains the differences between the findings of the current study 
and those of Kimura et al. (2006). In addition, it is possible that adaptations during onset of lactation in dairy cows that are not present in dry cows further suppress cytosolic stores of $\mathrm{iCa}^{2+}$ or the ability of leukocytes to uptake extracellular $\mathrm{iCa}^{2+}$. Also, the maximum ratio of cytosolic $\mathrm{iCa}^{2+}$ in lymphocytes was achieved at $470 \pm$ $34 \mathrm{~s}$, relatively near the end of the 660-s measurement interval in the current study, in contrast with the time observed for neutrophils $(191 \pm 11 \mathrm{~s})$. Therefore, the possibility exists that the 660 -s measurement interval might not have been sufficient to evaluate differences in the dynamics of cytosolic $\mathrm{iCa}^{2+}$ concentrations in lymphocytes.

The present study demonstrated the direct link between SCH and DMI, glucose metabolism, lipid mobilization, and innate immune function in dairy cows. These findings corroborate epidemiologic studies that connect early lactation $\mathrm{Ca}$ metabolism and risk of peripartum diseases, particularly those that affect the reproductive tract (Martinez et al., 2012). The ramification of these results includes the need to maintain proper blood Ca concentrations to minimize excessive tissue catabolism in early lactation.

The immediate increases in concentrations of plasma NEFA and glucose concurrent with decreased insulin indicate that insulin release by the pancreas was compromised in SCHI cows. Therefore, it is plausible that early lactation cows that undergo $\mathrm{SCH}$ face additional challenges to balance glucose metabolism and tissue catabolism. When extrapolated to early lactation cows, which typically have decreased DMI, negative energy balance, and immune dysfunction, development of SCH would further contribute to the severity of these conditions. The application of the current model to recently calved cows warrants further investigation to determine the role of SCH on metabolism and immune function of postpartum cows when undergoing adaptation to lactation.

\section{CONCLUSIONS}

Infusion of a solution of 5\% EGTA successfully induced $\mathrm{SCH}$ in dairy cows by chelating $\mathrm{iCa}^{2+}$ in blood and increasing the urinary excretion of Ca. Cows subjected to $\mathrm{SCH}$ excreted an amount of $\mathrm{Ca}$ in urine similar to that observed in colostrum during the first day postpartum. Cows with SCH had reduced DMI and rumen contractions and decreased concentrations of insulin in plasma, likely by compromised pancreatic release of the hormone, which explains the increased concentrations of blood glucose and lipid mobilization based on elevation in plasma NEFA concentrations. Cows induced to develop SCH had a faster decline of cytosolic $\mathrm{iCa}^{2+}$ in neutrophils after ionophore stimulation, which likely explains the compromised phagocytic and oxidative burst activities of these cells against pathogenic bacteria. Collectively, our results document the negative effects of SCH on DMI, energy metabolism, and function of innate immune cells in nonpregnant, nonlactating dairy cows and serve as a model to study the role of Ca metabolism on increased susceptibility to peripartum diseases. Increased risk of diseases observed in cows that develop $\mathrm{SCH}$ in early lactation might, in part, be caused by suppressed function of immune cells mediated by reduced cytosolic $\mathrm{iCa}^{2+}$ concentrations.

\section{ACKNOWLEDGMENTS}

The authors thank Gergeli Toldi (Semmelweis University, Budapest, Hungary) for helping us with the analysis of the intracellular calcium using FacsKin software and Eric Diepersloot (Dairy Unit, University of Florida, Gainesville) for assistance with the study. Appreciation is extended to Doug Ensley (Boehringer Ingelheim Vetmedica, St. Joseph, MO). Financial support for this study was provided by a student scholarship from Boehringer Ingelheim Vetmedica and by a grant from the Southeast Milk Check-Off Dairy Research and Education Projects.

\section{REFERENCES}

Allen, M. S. 2000. Effects of diet on short-term regulation of feed intake by lactating dairy cattle. J. Dairy Sci. 83:1598-1624.

Bréchard, S., and E. J. Tschirhart. 2008. Regulation of superoxide production in neutrophils: Role of calcium influx. J. Leukoc. Biol. $84: 1223-1237$.

Burgos, R. A., I. Conejeros, M. A. Hidalgo, D. Werling, and C. Hermosilla. 2011. Calcium influx, a new potential therapeutic target in the control of neutrophil-dependent inflammatory diseases in bovines. Vet. Immunol. Immunopathol. 143:1-10.

Cohen, M. S. 1994. Molecular events in the activation of human neutrophils for microbial killing. Clin. Infect. Dis. 18:S170-S179.

Curtis, C. R., H. N. Erb, and C. J. Sniffen. 1983. Association of parturient hypocalcemia with eight periparturient disorders in Holstein cows. J. Am. Vet. Med. Assoc. 183:559-561.

Daniel, R. C. W. 1983. Motility of the rumen and abomasum during hypocalcaemia. Can. J. Comp. Med. 47:276-280.

Ducusin, R. J., Y. Uzuka, E. Satoh, M. Otani, M. Nishimura, S. Tanabe, and T. Sarashina. 2003. Effects of extracellular $\mathrm{Ca}^{2+}$ on phagocytosis and intracellular $\mathrm{Ca}^{2+}$ concentrations in polymorphonuclear leukocytes of postpartum dairy cows. Res. Vet. Sci. 75:27-32.

Fukao, T., G. D. Lopaschuk, and G. A. Mitchell. 2004. Pathways and control of ketone body metabolism: On the fringe of lipid biochemistry. Prostaglandins Leukot. Essent. Fatty Acids 70:243-251.

Goff, J. P. 2008. The monitoring, prevention, and treatment of milk fever and subclinical hypocalcemia in dairy cows. Vet. J. 176:50-57.

Hansen, S. S., P. Norgaard, C. Pedersen, R. J. Jorgensen, L. S. Mellau, and J. D. Enemark. 2003. The effect of subclinical hypocalcemia induced by $\mathrm{Na}_{2}$ EDTA on the feed intake and chewing activity of dairy cows. Vet. Res. Commun. 27:193-205.

Hayirli, A. 2006. The role of exogenous insulin in the complex of hepatic lipidosis and ketosis associated with insulin resistance phenomenon in postpartum dairy cattle. Vet. Res. Commun. 30:749-774.

Horst, R. L., and N. A. Jorgensen. 1982. Elevated plasma cortisol during induced and spontaneous hypocalcemia in ruminants. J. Dairy Sci. $65: 2332-2337$. 
Horst, R. L. J. P., Goff, and T. A. Reinhardt. 2005. Adapting to the transition between gestation and lactation: Differences between rat, human and dairy cow. J. Mammary Gland Biol. Neoplasia 10:141-156.

Johnson, M. M., and J. P. Peters. 1993. Technical note: An improved method to quantify nonesterified fatty acids in bovine plasma. J. Anim. Sci. 71:753-756.

June, C. H., R. Abe, and P. S. Rabinovitch. 2001. Measurement of intracellular calcium ions by flow cytometry. Curr. Protoc. Cytom. 9:8.1-8.19. http://dx.doi.org/10.1002/0471142956.cy0908s02.

Kaposi, A., G. Toldi, G. Meszaros, B. Szalay, G. Veress, and B. Vasarhelyi. 2012. Experimental conditions and mathematical analysis of kinetic measurements using flow cytometry-The FacsKin method, Ingrid Schmid, ed. Flow Cytometry - Recent Perspectives. Accessed Jun. 13, 2013. http://cdn.intechopen.com/pdfs/37435/InTech-Experimental_conditions_and_mathematical_analysis_of_ kinetic_measurements_using_flow_cytometry_the_facskin_ method.pdf.

Kimura, K., T. A. Reinhardt, and J. P. Goff. 2006. Parturition and hypocalcemia blunts calcium signals in immune cells of dairy cattle. J. Dairy Sci. 89:2588-2595.

Larsen, T., G. Møller, and R. Bellio. 2001. Evaluation of clinical and clinical chemical parameters in periparturient cows. J. Dairy Sci. 84:1749-1758.

Littledike, E. T., D. A. Witzel, and S. C. Whipp. 1968. Insulin: Evidence for inhibition of release in spontaneous hypocalcemia. Proc. Soc. Exp. Biol. Med. 129:135-139.

Martinez, N., F. S. Lima, R. S. Bisinotto, L. F. Greco, E. S. Ribeiro, F. Maunsell, K. N. Galvão, C. A. Risco, and J. E. P. Santos. 2012. Evaluation of peripartal calcium status, energetic profile, and neutrophil function in dairy cows at low or high risk of developing uterine disease. J. Dairy Sci. 95:7158-7172.

Massey, C. D., C. Wang, G. A. Donovan, and D. K. Beede. 1993. Hypocalcemia at parturition as a risk factor for left displacement of the abomasums in dairy cows. J. Am. Vet. Med. Assoc. 203:852-853.

Melendez, P., G. A. Donovan, C. A. Risco, and J. P. Goff. 2004. Plasma mineral and energy metabolite concentrations in dairy cows fed an anionic prepartum diet that did or did not have retained fetal membranes after parturition. Am. J. Vet. Res. 65:1071-1076.

NRC. 2001. Nutrient Requirements of Dairy Cattle. 7th rev. ed. Natl. Acad. Press, Washington, DC.
Paape, M. J., D. D. Bannerman, X. Xhao, and J. W. Lee. 2003. The bovine neutrophil: Structure and function in blood and milk. Vet. Res. 34:597-627.

Parekh, A. B. 2006. Cell biology: Cracking the calcium entry code. Nature 441:163-165.

Quah, B. J. C., and C. R. Parish. 2012. New and improved methods for measuring lymphocyte proliferation in vitro and in vivo using CFSE-like fluorescent dyes. J. Immunol. Methods 379:1-14.

Reinhardt, T. A., J. D. Lippolis, B. J. McCluskey, J. P. Goff, and R. L. Horst. 2011. Prevalence of subclinical hypocalcemia in dairy herds. Vet. J. 188:122-124

Ribeiro, E. S., F. S. Lima, L. F. Greco, R. S. Bisinotto, A. P. A. Monteiro, M. Favoreto, H. Ayres, R. S. Marsola, N. Martinez, W. W. Thatcher, and J. E. P. Santos. 2013. Prevalence of periparturient diseases and impacts on fertility of seasonally calving grazing dairy cows supplemented with concentrates. J. Dairy Sci. 96:5682-5697.

Risco, C. A., J. P. Reynolds, and D. Hird. 1984. Uterine prolapse and hypocalcemia in dairy cows. J. Am. Vet. Med. Assoc. 185:15171519.

Rorsman, P., M. Braun, and Q. Zhang. 2012. Regulation of calcium in pancreatic $\alpha$ - and $\beta$-cells in health and disease. Cell Calcium 51:300-308.

Saris, N. E., and E. Carafoli. 2005. A historical review of cellular calcium handling, with emphasis on mitochondria. Biochemistry (Mosc.) 70:187-194.

Sordillo, L. M., and W. Raphael. 2013. Significance of metabolic stress, lipid mobilization, and inflammation on transition cow disorders. Vet. Clin. North Am. Food Anim. Pract. 29:267-278.

Valadares, R. F. D., G. A. Broderick, S. C. Valadares Filho, and M. K. Clayton. 1999. Effect of replacing alfalfa silage with high moisture corn on ruminal protein synthesis estimated from excretion of total purine derivatives. J. Dairy Sci. 82:2686-2696.

Van Soest, P. J., J. B. Robertson, and B. A. Lewis. 1991. Methods for dietary fiber, neutral detergent fiber and nonstarch polysaccharides in relation to animal nutrition. J. Dairy Sci. 74:3583-3597.

Vig, M., and J. P. Kinet. 2009. Calcium signaling in immune cells. Nat. Immunol. 10:21-27.

Witzel, D. A., and E. T. Littledike. 1973. Suppression of insulin secretion during induced hypocalcemia. Endocrinology 93:761-766. 